\title{
An Integrated QFD-FEA Framework for Evaluation of Nigeria Garment Designs
}

\author{
Adepeju A. Opaleye, PhD \\ Adekunle Kolawole, PhD \\ Industrial and Production Engineering, \\ University of Ibadan, Nigeria \\ Muyiwa A. Opaleye, PhD \\ Department of Business Administration, \\ Precious Cornerstone University, Ibadan, Nigeria
}

Doi:10.19044/esj.2020.v16n13p348 URL:http://dx.doi.org/10.19044/esj.2020.v16n13p348

\begin{abstract}
Consumers' perceived quality of imported product has been an impediment to business in the Nigeria garment industry. To improve patronage of made- in-Nigeria garment designs, the first step is to understand what the consumer expects, then proffer ways to meet this expectation through product redesign or improvement of the garment mass production process. The purpose of this study is to investigate drivers of consumers' value for typical Nigerian garment design (NGD). Using survey data from 522 respondents, an integrated quality function deployment (QFD) and functional, expressive and aesthetic (FEA) Consumer Needs methodology helps to minimize incorrect understanding of potential consumer's requirements in mass produced garments. Out of the sixteen identified quality characteristics, six themes emerged as drivers of consumer's satisfaction: (1) Style variety (2) Dimensions (3) Finishing (4) Fabric quality (5) Garment Durability and (6) Aesthetics. Existing NGD is found to lead foreign designs in terms of its acceptance for informal events, style variety and fit while there is a need for improvement of other quality characteristics. Local designers may consider adoption of QFD-FEA framework to improve quality of NGD, overall customer's acceptance and NGD mass production process. A conceptual model of NGD acceptance in the context of consumer's inherent characteristics, social and the business environment is proposed.
\end{abstract}

Keywords: Perceived quality, Garment design, Quality function deployment, FEA Model, Mass production 


\section{Introduction}

The increasing pressure in the global market now compels organizations to find better ways to meet consumer's needs. Companies in this competitive market introduce products with cutting edge features ahead of competitors. This is to ensure their consumers with a growing demand for unique and sophisticated products are satisfied. One of the ever-demanding and increasing markets is the Nigeria market (Adaramola and Kolapo, 2012; Chinedu, et al., 2010). Nigeria is a developing country with a mixed economy and an unstable GDP growth rate. This with the importation of consumer goods has created an intensely competitive business environment for local producers and manufacturers. Moreover, for some products and services, the tastes and preferences of Nigerians are beginning to converge on some global norms. This is hinged on the perceived quality of imported items. An example of such is fashion or clothing items which may also be sourced locally.

As one of the world's most globalized businesses and vulnerable sector, the Nigerian fashion industry, is non-resilient to the challenges associated with the unstable economic growth and unfavourable industrial policies. Even with the recent attempt by the government to revive the situation, studies have shown that there is an increased sense of value and admiration for imported garment items by Nigerians (Udegbe, 2017). It is therefore imperative that local designers should be aware and guided by preferences of Nigerians and its translation to global trends to have a competitive edge over foreign clothing designs within the Nigeria market. Furthermore, government and local designers may work together to break all barriers to harnessing the benefits of the Nigerian fashion industry as a critical component of the Nigerian economy, creating employment opportunities, promoting creativity, ingenuity and culture.

However, there are a few number of literature on Nigerian garment design (NGD) and production (Abubakar et al. 2018; Anikweze 2013; Kolawole, 2016; Opaleye, et al., 2019; Thompson, et al.,2015). Abubakar (2018) considered the dilemma of second-hand clothes and European way of dressing on the society, culture and Nigerian economy. A study by Thompson et al., (2015) examined the design innovation challenges encountered in the process of sustainable apparel product development in Nigeria. Kolawole (2016) and Oluah (2014) primarily focused on the duo issue of size and fit for ready-to-wear (RTW) production system in Nigeria.

Unlike many developed countries, where the acquisition of clothing or garment is basically via the ready-to-wear (RTW) production system, the prevalent method of acquiring NGD is custom made (Iloeje 2007); "cut and sew" or Visit-The-Tailor (VTT) (Opaleye, et al., 2019). While mass production involves the production of garments using standard body measurements system; custom-made or "cut and sew" or VTT entails sewing 
for individual consumers who purchase their fabrics and present them to dressmakers for use in producing specific garments style for their body measurements (Oluah 2014). Though the latter produces garments with a good fit, it has been found to fail the test of global quality elements such as price, delivery speed and availability.

Fit is an important issue in garment production. It may be defined as the way the garment forms to the body in the matter of tolerance and harmony with the covered body parts (Hernández, et al., 2018). Other researchers defined it as a consumer's overall satisfaction index, critical to garment selection or purchase (Pisut and Connell 2007). It could be observed that the term "fit" has a subjective meaning (Kasambala, et al., 2016). That is, consumers' perceptions of a garment fit may be influenced not only by the measured body or garment dimension but by some social and psychological needs (Kasambala, et al., 2016). According to Lamb and Kallal (1992), clothing items cater for three basic needs of the consumer; functional, expressive and aesthetic needs. Hence, to a consumer, the closeness of a garment dimension to a body measurement and some other implicit requirements make the fit as well as the willingness to purchase a garment item. However, to the best of the researcher's knowledge, there are few studies relating to the mass production of Nigeria garment designs from the consumer's perspective.

Nigerian traditional garment designs are considered as styles (commonly known as Iro and Buba, Agbada, Dansiki etc.) in local African fabrics such as Ankara, Adire etc. These are colourful African cotton print textile which expresses the African pride (Oyedele, A., Babatunde, 2013) while the foreign garments are designs in form of suits, denim jeans or garments by foreign designers such as Kelvin Klein, Versace commonly available in Nigerian stores. Hence, this study aims to identify consumer's requirement for Nigerian Garment designs and their perception on the fit of local and imported garment items for mass production purpose.

The Quality Function Deployment (QFD) method which incorporates the FEA model by Lamb and Kallal (1992) will be used to achieve these objectives.

\section{Literature Review}

Product development and improvement require concerted efforts of designers, developers and market experts to understand and integrate consumer's wants into product blueprint. Ineffective communication between these functional levels in product development or improvement may result in the introduction of products that do not meet consumer's expectations and eventual resource wastage. 
Quality Function Deployment is a consumer-oriented design tool with cross-functional team members reaching a consensus in developing a new or improved product to increase consumer satisfaction (Singh, et al., 2016). The Quality Function Deployment (QFD) methodology remains one of the commonly used tools for assessing and improving the performance of a product or service. Unlike other quality management tools, QFD creates a template for aggregating qualitative and quantitative quality data for product improvement (Dehe and Bamford 2017). It was first introduced in 1972 by a researcher known as Akao in his publication "hinshitsu tenkai" meaning "Quality Deployment". Since then, it has been in use by the Japanese for quality control and was adopted by the American in the 1980s.

Currently, companies around the world, Europe, China, India, and some nations of Latin America applies QFD for better performance in the competitive market (Yusuf and Gunasekaran, 2007). QFD has been applied as a tool to: improve quality of chemotherapy unit services (Hashemi et al., 2015), determine the best marketing strategy for the tube forming industry (Kulkarni et al., 2015), enhance healthcare infrastructure development (Dehe and Bamford 2017), evaluate consumer's perception on poultry foods (Naspetti, et al., 2015), improvement of academic curriculum design (Abuzid, 2017) and to determine the standard of service by consumer's needs (Purba, et al., 2018). However, there are a few studies on the application of QFD for the improvement of garment designs. Chen et al., (2014) illustrated how QFD may be used to improve service innovations for rapidly changing fashion trends while Kabukcu (2016) proffered QFD methodology for improvement and sustainability of fashions brands.

Importance of QFD for garment design problems can be summarized into three main areas: to prioritize explicit and implicit consumer requirements, to translate the consumers' needs into product design parameters and to obtain a quality product which satisfies consumers.

Similarly, the functional, expressive and aesthetic (FEA) Consumer Needs Model is user-centred. It is designed to identify the garment needs of the end consumer (Lamb and Kallal 1992). Although, it was originally developed as a teaching aid for student designers to conceptualise the design process, the model has been applied to relevant areas of functional design research including hospital gowns (Cho, 2006), men tennis clothing (Jin, 2010), women's sailing apparel (Bye and Hakala, 2005) and garment needs for adolescents with disabilities (Stokes and Black 2012). The model is an integrated design framework that may be applied for developing design criteria irrespective of the potential consumers.

FEA assesses functional, expressive and aesthetic consumer's requirements (Figure 1). The functional design process addresses the wearer's needs. For instance, Black and Cloud (2008) follow the concept of the 
functional design process for needs assessment of bicycle patrol officers' uniform. Thermal discomfort and fit issues affecting movement were identified by users and recommendation made for a uniform redesign. A similar study was conducted by Mitchka et al., (2009) to redesign adult female dance wears. The expressive requirement of a consumer, on the other hand, provides an opportunity for the wearer to communicate his or her self-image. According to Claudiu and Andreea (2014), consumers are willing to pay for a brand which suits their implicit need such as the perceived ideal identity. As a result, preference for a certain brand is an output of the need to express oneself i.e. only a result of sociological factors.

The aesthetic needs of the consumer are related to appeal of a clothing product or beauty in terms of style, colour, appearance, fashionability or attractiveness (Kasambala, et al., 2016; Wheat and Dickson 1999). Essentially, it contributes to wearer's identity, as well as the physical performanceenhancing characteristics (Dickson and Pollack 2000). In a study by Wheat and Dickson (1999), characteristics influencing interest in collegiate female golf uniforms was examined using the Comfortably Attractive Appearance scale. Hence, the FEA and QFD model may be appropriate for assessing the needs of NGD wearers.

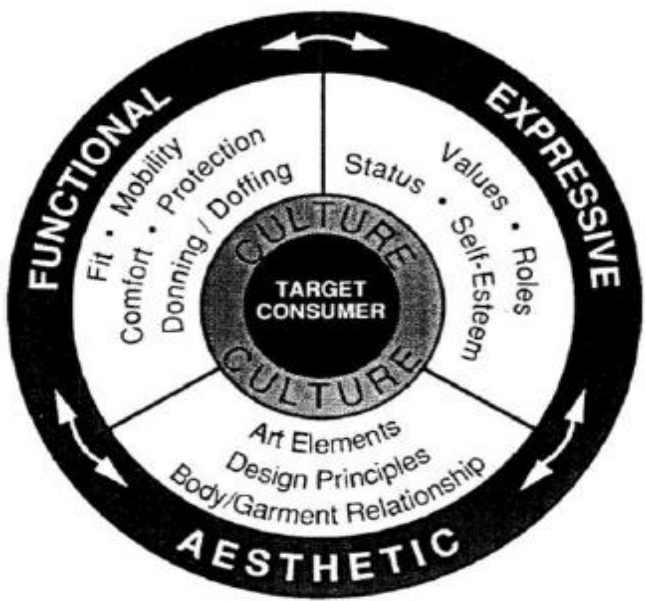

Figure 1. The FEA Consumer Needs Model. Source: Lamb and Kallal (1992, p. 42). Monument, CO. International Textile and Apparel Association. Copyright 1992 by International Textile and Apparel Association.

\section{Research Method}

The main question of this study is "what do consumers want from Nigerian garment designs?". To answer this question, an exploratory approach 
using the integrated QFD-FEA model is designed to investigate the research question from the consumer's perspective.

\section{The QFD-FEA model}

This section explains the application of the integrated Quality Function Deployment and Functional, Expressive and Aesthetic methodology in the exploratory study. It is specifically tailored to assess consumers' requirements for Nigerian garment designs. The House of Quality (i.e. the Product Planning Matrix) which is the main matrix of QFD is as shown in Figure 2.0. It is a structured and systematic way of translating consumer's expectation (CE) for a product into the prioritized design or technical requirements (DTR) that can be further deployed to develop production process and product provision plans. The sections are as follows:

\section{- Whats Section}

Step 1: Identify Consumer's Quality Expectations (needs and wants) (Room 1)

It is the voice of consumers (VOC) section. In the current study, Nigerians of all ages are considered as potential consumers of Nigeria Garment Designs (NGD). To identify the needs of this group, problems associated with mass customization and quality of NGD was discussed intermittently across different focus groups. The focus group was based on the homogeneity or similarity of the members. This helps to understand consumer's perception of Nigeria Garment Designs (NGD), foreign Garment Designs (FGD) and identify their expectations.

Step 2: Determine the Relative Importance Factor of "WHAT"(Room 2)

Once these expectations or required qualities had been identified, a structured questionnaire was designed based on the FEA consumer Need Model and the relative importance rating of each item calculated.

\section{- Hows Section}

\section{Step 3: Determination of design and technical requirements (DTR)} (Room 3)

It is the voice of designers (VOD) section. This includes design features and technical requirements considered appropriate for market purpose. Perceptions of quality from home-based fashion designers and retailers were explored to develop an understanding of what they think about the garment's quality characteristics and how this relates to patronage. A convenience sampling of home-based male and female experts was conducted within a city in Nigeria. These experts were selected based on the acquired practical experiences in garment making and retailing. The experts offered their views on the garment quality characteristics and the identified factors 
were used to structure the questionnaire in a close-ended form with items rated on a 5-point Likert scale.

\section{- Roof Section}

\section{Step 4: Establish correlation between DTR of garment items (Roof)}

This stage involves the determination of how DTRs interact with each other. The interactions between DTR may be determined using the convention of the roof ranking system. The roof interaction matrix ranges from strong positive correlation to strong negative correlation as shown in Table 1.0. To determine the consensus of the pairwise interactions, the conventions were assigned numerical values and analysed using the Pearson correlation function.

\section{- Mainroom Section}

\section{Step 5: Establish Interaction between HOWs and WHATs (MainRoom)}

After establishing the "whats" and "hows", construction of the house of quality continues with establishing the relationships between the HOWs and WHATs. The HOWs are ranked according to their correlation of fulfilling the HOWs (Kulkarni et al. 2015). Researchers (Dehe and Bamford 2017; Hashemi, et al., 2015; Kulkarni, et al., 2015; S., Naspetti, et al., 2015) assert that this relationship matrix is the key component of the Quality Function Deployment. Each relationship can be assessed independently and symbols for each of correlation which correspond to numerical values are assigned as shown in Table 2.0.

\section{- Competitive Assessment \\ Step 6: Competitive Comparison}

This is the comparison of the NGD and FGD in fulfilling the "WHATS". It represents the current performance of NGD and FGD as perceived by the consumers and is obtained by finding the average over all of the samples of the administered questionnaire. Here, the overall perception of consumers for NGD and FGD was also evaluated. It is hypothesised that;

(i) there is no significant difference between consumer's expectation and their perceptions on NGD,

(ii) there is no significant difference between consumer's expectation and their perceptions on FGD,

(iii) there is no significant difference between consumer's overall perceptions on NGD and FGD. 


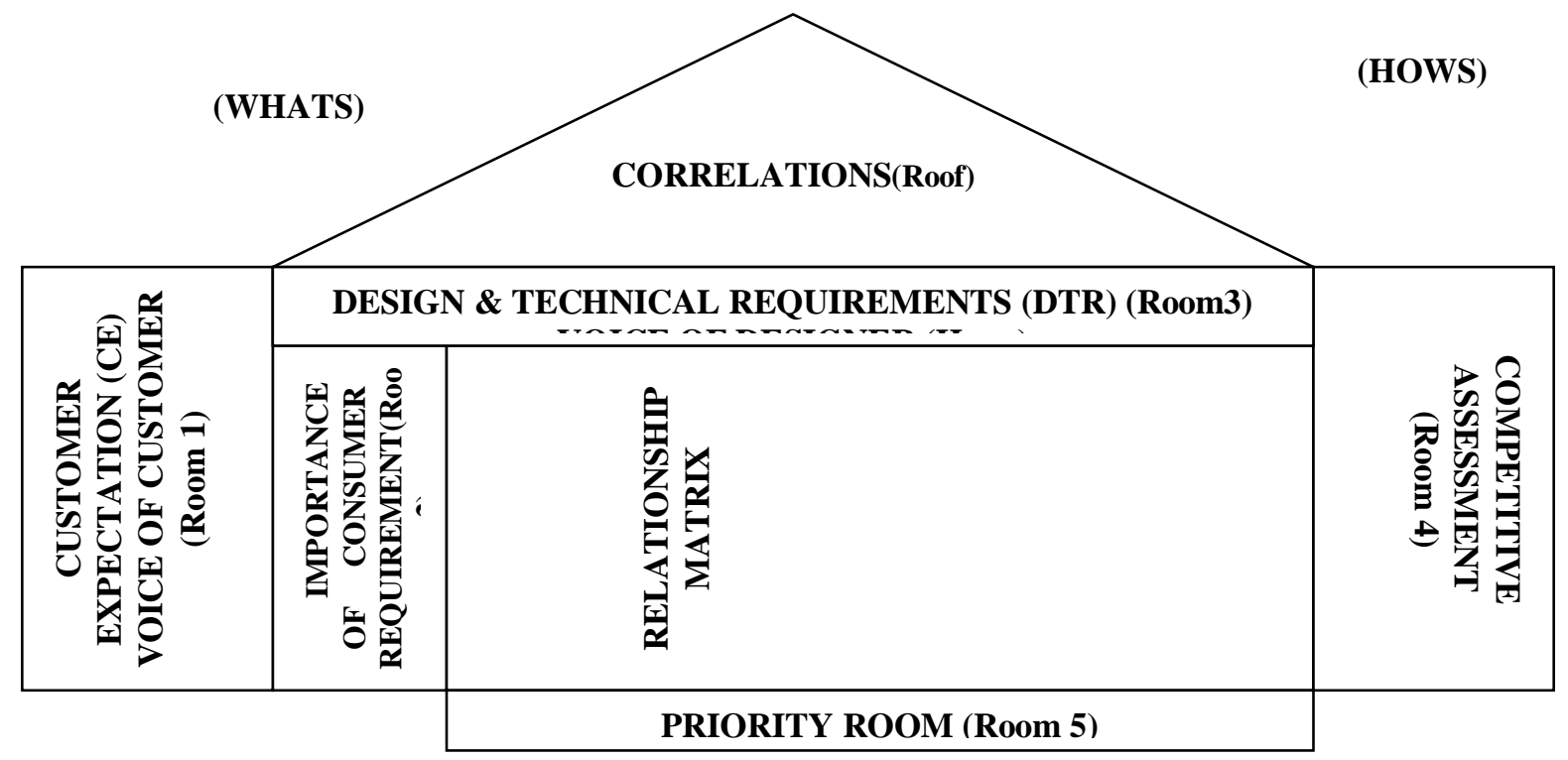

Figure 2. House of Quality

Table 1: Roof ranking system

\begin{tabular}{|c|c|c|}
\hline INTERACTIONS & CONVENTION & CODE \\
\hline - $\quad$ STRONG POSITIVE INTERACTION & - ++ & - $\quad+2$ \\
\hline - $\quad$ POSITIVE INTERACTION & - + & - $\quad+1$ \\
\hline - $\quad$ NO INTERACTION & $\bullet$ & - $\mathbf{0}$ \\
\hline - NEGATIVE INTERACTION & - $\quad-$ & - $\quad-1$ \\
\hline - $\quad$ STRONG NEGATIVE INTERACTION & - $\quad-$ & $\begin{array}{ll}-2 \\
\end{array}$ \\
\hline
\end{tabular}

Table 2: Relationships, symbols and their weighting factors

\begin{tabular}{|c|c|c|}
\hline - RELATIONSHIP & - SYMBOL & $\begin{array}{l}\text { - WEIGHTING } \\
\text { FACTOR }\end{array}$ \\
\hline $\begin{array}{ll}\text { - } & \text { STRONG } \\
\text { - } & \\
\text { - } & \text { MEDIUM } \\
\text { - } & \\
\text { - } & \text { WEAK } \\
\text { - } & \text { NO CORRELATION }\end{array}$ & $\begin{array}{l}\text { - } \\
\cdot \\
\cdot \\
\cdot\end{array}$ & $\begin{array}{ll}- & 9 \\
\bullet & \\
- & 3 \\
- & 1 \\
- & 0\end{array}$ \\
\hline
\end{tabular}

\section{Step 7: Improvement Ratio}

This is the rate at which design must be adjusted to reach the expected level. It is calculated by dividing the base importance of consumer's quality requirement by the current perception of the quality of NGD and FGD. 


\section{Step 8: Relative Importance of "HOWS"}

This is obtained by calculating the total of the sums of each column when multiplied by the base importance factor. It is useful for ranking each of the "HOWS" and determining when to allocate resources.

\section{Step 9: Recommend actions by which NGD can be improved (Room 5)}

The quality characteristics of the product may be determined by brainstorming. This activity ensures that the qualities generated represent a list of what designers can measure and control to satisfy consumer's requirements.

\section{Discusion of Result}

A total of 522 online and offline responses $(73.6 \%$ male and $23.5 \%$ female) were received. Of the 522 respondents, $4.4 \%$ are less than 20years, $46.2 \%$ are between 20 and 29years, $30.8 \%$ between 30 and 39, $15.4 \%$ between 40 and 49 and 3.3\% above 50 years. According to Krejcie and Morgan (1970), this is a sufficient number for a population of over 100,000.

From the semi-structured questions, consumer's perception of fit and acceptance of NGD were explored and used to develop the FEA-based forms. Responses to the functional, expressive and aesthetic needs of the potential consumers regarding typical Nigeria designs were analyzed. While expressive considerations were most often reported for NGD, respondents also indicated some functional and aesthetic considerations. Irrespective of the age, the main functional consideration identified is the fit. Garment fit is about the numerical difference between the dimensions of the garment and those of the consumer; it also allows for easy movement. Expressive considerations identified can be summarised as; acceptability and suitability of design to consumer's work environment and personality while the aesthetic considerations for the NGD include fabric type, colour and beauty. Other consumer's requirements include; designer/brand name, ease of access through the online market and offline stores/markets. This is presented in the first column of the NGD HOQ (Figure 3).

Each of these items in room 1 is rated on a 5-point Likert-type scale with endpoints of strongly. Column 2 of the table presents the relative base importance value for each of the expectations for an ideal garment item. This is the planning phase in relation to consumer demands. A critical look into the VOC may allow further investigation of the factors impacting NGD acceptance. As many of the consumer's concerns relate to; inherent characteristics, social characteristics, and the business environment.

The opinion of eighteen (18) designers and retailers (88.9\% are female and $0.11 \%$ are male) with at least five (5) years of experience in the area was obtained. During the interactive sessions, the DTRs for garment items selected by the fashion designers and retailers are as follows: Accuracy in garment 
dimension, seamline, style, fabric quality, fabric weight, aesthetics, draping capacity, durability, breathability and good finishing or neatness. This forms the HOWs of room 3 in the NGD HOQ. Further evaluation of the designers and retailers assessment forms for the DTRs resulted in 55 DTR pairwise comparison and the Pearson correlation is presented in Figure 3. To translate the consumer's needs into a better product, it is necessary to determine how much each of these DTR affects each of the consumer's required quality. The main room of Figure 3.0 shows the relationship between the WHATs and HOWs. This information is also known as the relationship matrix.

The competitive assessment stage of NGD HOQ development represents the current performance of NGD and FGD as perceived by the consumers and the improvement ratio at which NGD must be adjusted to reach consumers expected level. For instance, column 13 of Figure 3 shows that consumers perceive that size of NGD is more appropriate compared to the foreign designs. This may be associated with the mode of acquisition which is basically through the "VTT". The assessment reveals that it is easier to acquire NGD through VTT compared to the offline or online market. Also, NGD is perceived as inappropriate or unsuitable for formal events. However, further improvement may not be required if NGD is considered for only social events.

The analysis helps to find the total merit of both NGD and FGD, according to the perception of the consumer. This shows precisely in what areas of the required qualities lag exist. The figure also shows that style variety is a key driver of consumer satisfaction with a relative percentage weight of $29.8 \%$, followed by the accuracy of garment dimension which determines fit and individual garment sizes (13.97\%), good finishing, fabric quality, garment durability and aesthetics which have relative percentage weights of $13.18 \%$, $11.66 \%, 9.65 \%$ and $9.62 \%$ respectively.

Table 3.0:Evaluation of the Hypotheses: t-Test: Paired Two Sample for Means

\begin{tabular}{|l|l|l|l|l|l|l|}
\hline & $\begin{array}{l}\text { Ideal } \\
\text { value }\end{array}$ & NGD & Ideal value & FGD & NGD & FGD \\
\hline Mean & 3.892 & 3.514 & 3.891 & 4.17675 & 3.5136 & 4.1767 \\
\hline Variance & 0.175 & 0.522 & 0.1755 & 0.420259 & 0.5223 & 0.4203 \\
\hline Observations & 16 & 16 & 16 & 16 & 16 & 16 \\
\hline Pearson Correlation & 0.386 & -0.0821 & & -0.5471 & \\
\hline Degree of freedom & 15 & 15 & & 15 & \\
\hline t Stat & 2.221 & -1.423 & -2.1988 & \\
\hline P(T<=t) two-tail & 0.0421 & 0.1749 & 0.0439 & \\
\hline t Critical two-tail & 2.1314 & 2.1314 & & 2.1314 & \\
\hline
\end{tabular}

The FEA model allows further analysis of the overall perception of consumers to NGD, FGD and consumer's ideal design as presented in Table 3.0. Evaluation of the first hypothesis with a two-tailed t-test shows a ' $t$ statistic' of 2.221 and p-value of 0.0421 . This implies that a significant 
difference exists between the consumer's expectation of an ideal design and their perception of NGD. Therefore, the null hypothesis is rejected. Similarly, for the third hypothesis, it is observed that there is a significant difference between the overall customer's perceptions on NGD and FGD given the $t$ value of -2.1988 with a p-value of 0.0439 . However, because the p-value of the second ( $\mathrm{t}$ statistic $=-1.423$ ) hypothesis for the two-tailed test is 0.1749 , the null hypothesis is not rejected. The data provide insufficient evidence to conclude that the overall expectation of the customer is significantly different from their perception of FGD. 
Figure 3: NGD HOQ

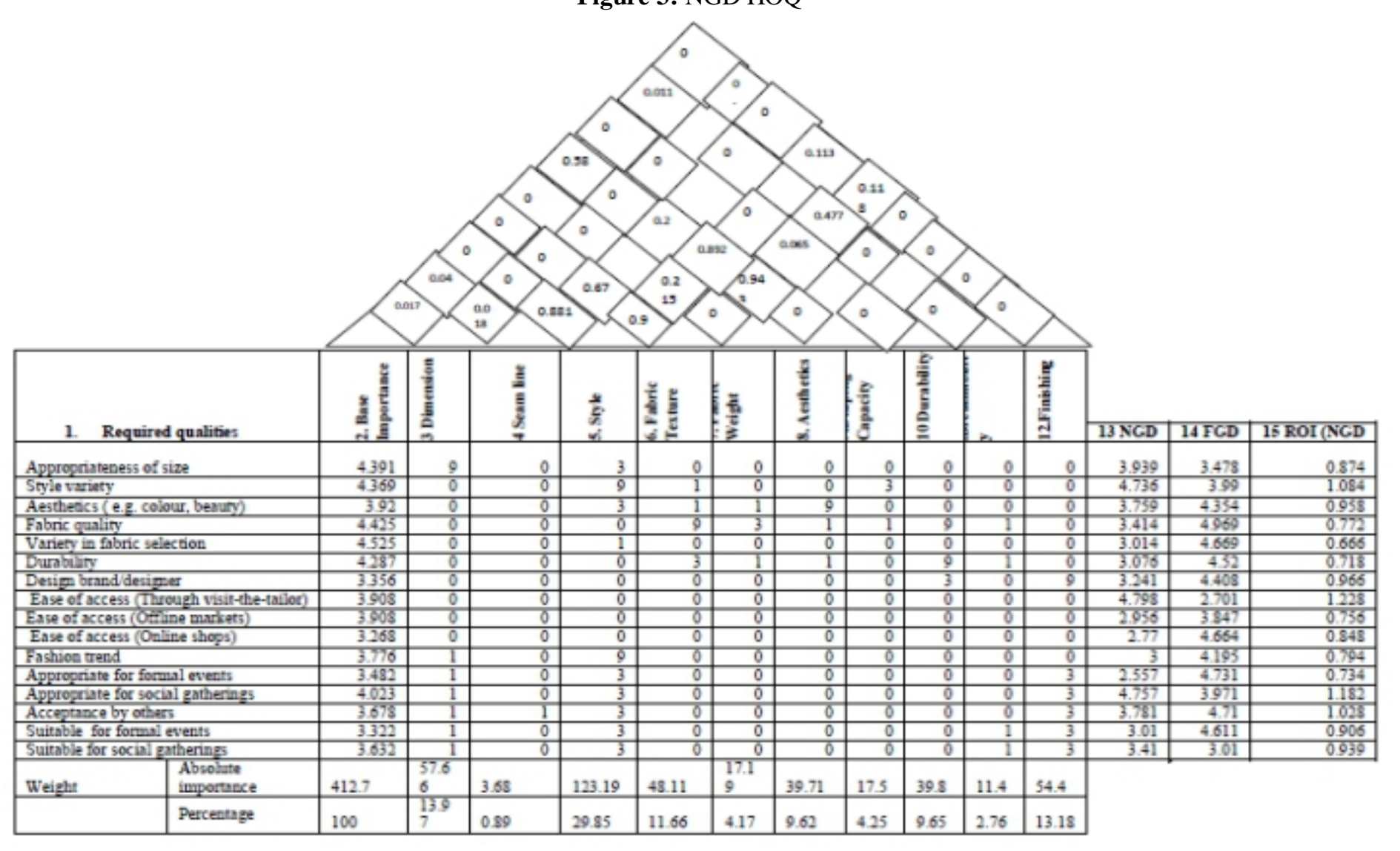




\section{Conclusion}

QFD is a planning tool for product improvement. It ensures that designers or producers capture customer's quality requirements in the product development stage. FEA model enhances understanding of consumer's need to garment item. In this study, sixteen dimensions of the customer's needs were identified. Fit and durability of garment designs relate to garment utility i.e.functional needs. Appropriate, suitable and acceptable design for formal and informal events relates more to expressive needs while colour, beauty, variety of fabric and style relate to the aesthetic needs of the customers. According to the customers, Nigeria Garment Designs lag behind the Foreign Garment Designs brands in many areas except size, style variety, ease of access through VTT, appropriate and suitable for social events. Since the focus of the study is on mass production of typical Nigerian garment designs, the result shows that there is room for improvement to meet the quality requirements of the consumers and increase patronage of made-in-Nigeria products. Existing designs may be improved to suit the workplace; technology may be harnessed to ensure products are available both in stores and online markets.

The present study has some limitations. The respondents consisted of male and female students and most of the responses were through google form with little information on respondents understanding of the context. Though the questions were considered explicit, face-to-face interaction with respondents with a semi-structured questionnaire may be considered more appropriate. Therefore, caution is needed when generalising the findings of the study. Furthermore, a conceptual model of NGD acceptance in the context of inherent customer characteristics, social and the business environment is proposed.

\section{References:}

1. Abubakar, M., Oluyemi, J., Abdulateef, R., Atolagbe, E., Adejoke, J. \& Williams, T. M. (2018). Imperialism and Loss of identity in second hand clothes: The Nigerian Okrika experience. Journal of Language, Technology and Entrepreneurship in Africa, 9(1), 151-72.

2. Abuzid, H.F.T.(2017). Applying QFD tools for quality improvements in curriculum design and teaching strategies to meet with the customer (Learner) Needs. Journal of Engineering and Applied Sciences, 12(3), 684-90.

3. Adaramola, F.T., \& Kolapo, A. O. (2012). The impact of the Nigerian capital market on economic growth (1990-2010). International Journal of Developing Societies, 1(1), 11-19. 
4. Anikweze, G.U. (2013). Figure types and the challenges of making garments in Nigeria. Production Agriculture and Technology, 9(1), 135-46.

5. Black, C., \& Cloud, R. (2008). Assessing functional clothing needs of bicycle patrol officers. International Journal of Fashion Design, Technology and Education, 1, 1-8.

6. Bye, E., \& Hakala, L. (2005). Sailing apparel for women: A esign development case study. Clothing and Textile Research Journal, 23, 45-55.

7. Chen, C., Lin, R., Chen, S.,\& Zhang, A. (2014). Exploring a SEEBASED service innovation for the fast fashion apparel industry- A case study of the fashion institute of Taipei in Taiwan. International Journal of Information Technology and Business Management, 30(1), $1-14$.

8. Chinedu, Ezirim. Aloy., Okeke, C. Titus ., \& Ebiriga, O. Thaddeus. (2010). Achieving vision 2020 in Nigeria: A review of the economic and market-oriented business reforms. Journal of Sustainable Development in Africa, 12(4), 58-71.

9. Cho, K. (2006). Redesigning hospital gowns to enhance end users ${ }^{\text {ee }}$ satisfaction. Family and Consumer Sciences Research Journal, 34, 332-349.

10. Claudiu, Munteanu. \& Pagalea. Andreea.(2014). Brands as a means of consumer self-expression and desired personal lifestyle. 2nd World Conference On Business, Economics And Management - WCBEM 2013 Brands, 109, 103-7.

11. Dehe, B., \& Bamford, D. (2017). Quality function deployment and operational design decisions - a healthcare infrastructure development case study Benjamin. Production Planning \& Control The Management of Operations, 28(14), 1177-1192.

12. Dickson, M. A., \& Pollack, A. (2000). Clothing and identity among female In-Line skaters. Clothing and Textiles Research Journal, 18, 65-72.

13. Hashemi, Neda., Marzban, M., \& Delavari, S. (2015). Quality function deployment: Application to chemotherapy unit services. Middle East Journal of Cancer, 6(4), 219-28.

14. Hernández, Niina, Heikki Mattila, \& Lena Berglin. (2018). A systematic model for improving theoretical garment fit. Journal of Fashion Marketing and Management: An International Journal, 22(4), 527-39.

15. Iloeje, C. I. (2007). Development and testing of block patterns for female youths in Enugu State Tertiary Institutions." University of Nigeria, Nsukka. 
16. J. Kasambala, E. Kempen, \& R. Pandarum. (2016). Determining female consumers' perceptions of garment fit, personal values and emotions when considering garment sizing. International journal of consumer studies, 40(2), 143-51.

17. Jin, H. (2010). Assessment of men's tennis clothing: Movement and aesthetic analysis. Washington State University.

18. Kabukcu, Evrim. (2016). A research on QFD- "House of Brand" in fashion industry." Chinese Business Review, 15, 207-213.

19. Kirsanova, E A, E A Chalenko, Yu S Shustov, \& G. V. Sanzhieva. (20150. Application of Quality function deployment method for determining performance properties of sports wear. Fibre Chemistry, $47(2), 62-64$.

20. Kolawole, A. (2016). Investigation of the relationship between fit and garment sizing parameters. University of Ibadan, Nigeria.

21. Krejcie, R. V., \& Morgan, D. W. (1970). Determining sample size for research activities. Educational and psychological measurement, 30.(3): 607-10.

22. Kulkarni, A.D., Bhalerao, A.S. Dabade, B.M., and Naphade, J.G. (2015). Quality function deployment in tube forming industry: A case study. Journal of Material Science and Mechanical Engineering (JMSME, ) 2(5): 415-19.

23. Lamb, J., \& Kallal, M. (1992). A conceptual framework for apparel design. Clothing and Textile Research Journal, 10(2), 42-47.

24. Mitchka, J., Black, C., Heitmeyer, J., \& Cloud, R. M. (2009). Problem structure perceived: Dance practicewear needs of adult female dance students."Clothing and Textiles Research Journal, 27, 31-44.

25. Oluah, Ekwutosi Beatrice. (2014). Development Of Standard Apparel Sizing System For Women In Nigeria. University of Nigeria, Nsukka.

26. Opaleye, Adepeju Abimbola, Adekunle Kolawole, \& Oliver Ekepre Charles-owaba. (2019). "Application of Fuzzy Clustering Methodology for Garment Sizing. 4(1), 24-31.

27. Oyedele, A., \& Babatunde, O. (2013). The Resurgence of „Ankara Materials in Nigeria. Journal of Education and Practice, 4(17), 166170.

28. Pisut, G.,\& Connell, L. J. (2007). Fit Preferences of Female Consumers in the USA. Journal of Fashion Marketing and Management, 11(3), 366-379.

29. Purba, H.H., Parid, M., Prasetyo, R.D.,\& Jina, R. (2018). Service development strategy with Quality function deployment (QFD) approach: A case study in banking service in Indonesia." International Journal of Advances in Scientific Research and Engineering (ijasre), 4(1), 40-47. 
30. S., Naspetti, Alberti,F., \& Solfanelli,F. (2015). Quality function deployment in the organic animal food sector: Application to poultry meat. Italian Journal of Animal Science, 14(4050): 544-50.

31. Singh, Shailender, Science Pilani, \& Manish Kumar. (2015). Product Development through QFD Analysis Using Analytical Network Process. International Journal of Advanced Engineering Research and Applications (IJAERA), 1(3), 112-26.

32. Stokes, Bailey, and Catherine Black. (2012). Application of the Functional,Expressive and Aesthetic Consumer Needs Model:Assessing the Clothing Needs of Adolescent Girls with Disabilities. International Journal of Fashion Design Technology and Education, 1-8.

33. Thompson, D., Okon, U. U.,\& Nwonye, N. U. (2015). Design innovation challenges and coping strategies of sustainable apparel product development among fashion designers in Uyo , Nigeria. Journal of Emerging Trends in Economics and Management Sciences, 6(8): 412-18.

34. Udegbe, S.E. (2017). Nigerian shoppers/consumers preferences for foreign and domestic products: Case study of clothes and shoes. Journal of Accounting \& Marketing, 6(4): 258.

35. Wheat, K.L.,\& Dickson, M.A. (1999). Uniforms for collegiate female golfers: Cause for dissatisfaction and role conflict? Clothing and Textile Research Journal, 17, 1-10.

36. Y Yusuf, A Gunasekaran, G. \& Dan. (2007). Implementation of TQM in China and organisation performance: An empirical investigation. Total quality management, 18(5): 509-30. 